\title{
Identification of Factors Affecting Mother-Infant Bonding in Advanced Maternal Age
}

\author{
Esma Gulturk, Oznur Korukcu* and Kamile Kukulu \\ Department of Nursing, University of Akdeniz, Turkey
}

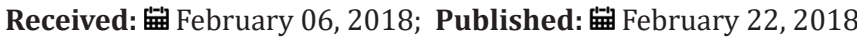

*Corresponding author: Oznur Korukcu, Department of Nursing, University of Akdeniz, Turkey

\begin{abstract}
Objective: Advanced maternal age has been associated with adverse pregnancy outcomes such as increased perinatal mortality, preterm delivery, and low birth weight. To identify the factors affecting the level of mother-infant bonding in advanced maternal age.

Methods: The present study was conducted at Akdeniz University Hospital and Antalya Training and Research Hospital between September 1st and December 31st, 2015. Statistics that describe the introductory information were provided along with the values of frequency, percentage, mean and standard deviation. Independent variables were categorical, logistic regression model was employed to identify the factors affecting the mother-infant bonding. Mother's educational attainment, employment status, occupation, spouse's age, educational attainment, occupation, and family's income do not have any effect on the mother-infant bonding.
\end{abstract}

Results: The number of children in the family adversely affects the bonding by the mother. By comparing the mothers that had caesarean-section with the mothers that had a normal delivery, it is seen that the probability of bonding is higher for mothers that had caesarean -section than the mothers that had a normal delivery. It was found that advanced age positively affected maternal bonding.

Conclusions: Mother-infant bonding after advanced age pregnancies should be carefully considered, and studies should be conducted involving advanced age gravidas and normal gravidas.

Keywords: Mother-infant bonding; Advanced maternal age; Maternal attachment; Motherhood; Maternity

\section{Introduction}

The definition of advanced maternal age is used for mothers at 35 years of age or older [1-3]. For the last few years, advanced maternal age has been the rising trend particularly in high-income countries [4]. Socioeconomic level, educational requirement, second marriage, lack of knowledge of contraception methods, and intention to stay in the workforce may increase the childbearing age above 35 [5,6]. A significant change has occurred in the agespecific fertility pattern in Turkey. While the overall fertility rate was 4.33 in 1978, it fell to 2.26 in 2013. Additionally, the agespecific fertility rate in pregnant women at 35 years of age or older was 143 per mile, whereas it decreased to 64 per mile in 2013. While the age-specific fertility rate was the highest in the age group 20-24 until TNSA-2003, it started to be distributed more evenly in the age-group 20-34 in TNSA-2003 and afterwards. According to TNSA-2013 data, the live-birth rates in pregnant women below and

above 35 years of age are $3.87 \%$ and $8.36 \%$, respectively [7]. As to the overall incidence in the world, $14 \%$ of the pregnancies occur at 35 years of age or older [8].

Several studies were conducted that showed advanced age pregnancy was associated with the increase in maternal and neonatal problems $[2,9,10]$. In some studies, miscarriage, stillbirth, preeclampsia, gestational hypertension, gestational diabetes, mellitus, preterm birth, low or high weight birth, and emergency or elective caesarean section were attributed to advanced maternal age. In addition to the studies investigating the effect of advanced maternal age on birth outcomes, there are also studies, albeit limited in number, that address the effect of advanced maternal age on mother's psychology, adaptation of maternal role, and maternalinfant bonding [11-14]. Walker, Crain and Thompson said that the age variable affected parental behaviour; likewise, Mercer and 
Walker stated that the age was an important variable in acquiring the maternal role. Stark indicates that the acceptance of maternal role in gravidas above 35 years of age is higher than in young gravidas $(<25)$. In the same study, it was also found that the levels of readiness for delivery in gravidas above 35 years of age were better than those in younger gravidas $(<25)$.

In their stud on 3,005 women, Kinsey and Hupcey found that the level of postpartum bonding of women at advanced ages was lower. In a study conducted in Turkey, it was found that maternal age significantly affected the mother-infant interaction in the early postpartum period [15]. Another study indicated that there was a positive relationship between the maternal age and maternal behaviour, meaning that more advanced maternal ages could provide more favourable maternal behaviour [16]. On the other hand, another study delving into the factors affecting the motherinfant bonding during pregnancy noted that the effect of the maternal age could not be identified [17]. A study conducted by Figueiredo, Costa, Pacheco and Pais showed that maternal age did not influence the emotional interaction and bonding between the mother and the infant [18]. The present study was conducted with a view to identifying the factors affecting the level of mother-infant bonding in advanced age pregnancies.

\section{Materials and Methods}

\section{Research Design}

The present study is a descriptive study with a survey model, and was conducted at Akdeniz University Faculty of Medicine and Antalya Training and Research Hospital between September 1st and December 31st, 2015.

\section{Setting and Sample}

Population of the research consists of the mothers of advanced maternal age who gave birth in the obstetrics clinics of Akdeniz University Faculty of Medicine and Antalya Training and Research Hospital in Antalya. Using the software package G Power 3.1.3., the medium effect size was found to be 0.05 , with the random error being 0.85 and the sample size being 118. Among the mothers of advanced maternal age who had recently given birth at Akdeniz University Faculty of Medicine and Antalya Training and Research Hospital, interviews were made with literate mothers above 35 years of age, who met the research criteria during the research, consented to participate in the study, and had a healthy baby which had been roomed-in after the birth.

\section{Data Collection Procedure}

The data for this study were collected by way of questionnaire. The questionnaire consists of two sections. The first section is the "Mother-Infant Introduction Form", and the second section is the "Mother-to-Infant Bonding Scale" (MIBS).

\section{Mother-Infant Introduction Form}

This was developed by the researchers upon a literature review, and is composed of 30 questions regarding introductory information on the mother, fertility and the baby.

\section{Mother-to-Infant Bonding Scale}

Mother-to-Infant Bonding Scale was developed by Taylor et al. [19]. It was translated to Turkish and its validity and reliability were tested by Karakulak- Aydemir and Alparslan [20]. It was reported that the inter-rater reliability of the scale was 0.71 , and the internal consistency reliability (average correlation coefficient among the items) was 0.66 (Cronbach's alpha). The Cronbach's alpha (internal consistency reliability coefficient) for the present study was found to be 0.92 . The scale was arranged in such a manner as to be able to be applied as from the first day postpartum, and allows the mother to express her emotions towards her baby in a single word. It can be applied easily and quickly by the mother and the father by themselves, and shows the relationship between the bond and the early postpartum mood of the mother. Mother-toInfant Bonding Scale is a 4-point Likert scale consisting of 8 items. The responses to the 4-point items are scored between 0 and 3, meaning that the lowest and highest scores that can be obtained are 0 and 24, respectively. As the scale score increases, the level of bonding decreases. In the scale, the items 1, 4 and 6 are statements about positive emotions and are scored from 0 to 3 , whereas the items 2, 3, 5, 7 and 8 are statements about negative emotions and are scored backwards, that is, from 3 to 0 .

\section{Ethical considerations and the Collection of Data}

The written permission of the heads of Akdeniz University Hospital and Antalya Training and Research Hospital was obtained for the study. Also, the ethics committee approval was obtained from the Akdeniz University Faculty of Medicine Non-entrepreneurial Clinical Research Ethics Committee (Approval no: 2015/205). The permission was shown and the purpose of the study was explained to the participants who agreed to participate and gave their oral and written consent.

\section{Data analysis}

OpAnalyses were conducted using SPSS 19.00. Statistics that describe the introductory information relating to the mother, fertility-related information and introductory information relating to the infant were provided along with the values of frequency, percentage, mean and standard deviation. Cronbach's alpha analysis was conducted in an attempt to test the internal consistency of the questionnaire. The responses given by the participants to the questions of the mother-to-infant bonding scale were subjected to cluster analysis, as a result of which a two-cluster solution was obtained. Those falling into the first cluster were the mothers bonded to their infants, and were coded as 1 in the dependent 
variable. Those in the second cluster were the mothers not bonded to their infants, and were coded as 0 in the dependent variable. The cluster analysis showed that the mothers bonded to their child were $65.3 \%$ of the participants, whereas the mothers not bonded to their infants were $34.7 \%$ of the participants.

Independent variables were divided into two groups. The first group included demographic variables such as the mother's age, educational background, employment status, and profession as well as her spouse's age, educational background and profession. The second group included information such as the mother's number of children in her previous pregnancy and in her current pregnancy, condition of pregnancy planning, mode of delivery, infant's sex, condition of feeling ready for maternity, condition of receiving information and support in baby care as well as information on when the mother saw and cuddled her infant. In this study where the majority of the dependent variables (mother-infant bonding) and independent variables were categorical, logistic regression model was employed to identify the factors affecting the motherinfant bonding.

\section{Results}

The percentages and frequency distribution of the sociodemographic characteristics of the mothers involved in the study are summarised in Table 1 below ( $\mathrm{N}=118$ mothers). Average age of the participants is $38.08 \pm 2.78$ (min: 35 and max: 52). The percentages of employed and non-employed participants are $19.5 \%$ and $80.5 \%$, respectively. As to the educational attainment, $43.2 \%$ of the participants have a primary or elementary school diploma, $39 \%$ have a high school diploma, and $17.8 \%$ have a bachelor's or higher degree. As to the family type of the participants, nearly all of them (96.6\%) come from a nuclear family (Table 1). Most of the participants (74.6\%) are primipara. Half percentage of the current pregnancies of the participants are intended and planned, whereas 9.3\% are unintended. The rate of mothers reported that they had had a problem during pregnancy was $9.3 \%$ and $0.8 \%$ reported she (only one mother) had had a problem during delivery. As to the mode of delivery, $60.2 \%$ delivered their babies by C-section and $39.2 \%$ had normal vaginal delivery. Regarding the sex of the infants, $51.7 \%$ are female and $48.3 \%$ are male. Furthermore, nearly all of the participants (84.7\%) reported that their baby was of the sex they preferred, and $83.1 \%$ of the participants reported that their baby was of the sex their spouse preferred. It is reported that $45.8 \%$ of the participants had felt happy and $22 \%$ that they had felt joyful and excited when they had cuddled their baby. It is found that $75.4 \%$ of the mothers received support for baby care. On the other hand, $61.9 \%$ of the mothers did not receive any information on baby care after the delivery. Nearly all of the participants (95.8\%) stated that they felt ready for maternity, and $88 \%$ reported they did not use any nickname for their baby (Table 2).

Table 1: Distribution of the introductory information of the mothers.

\begin{tabular}{|c|c|c|}
\hline Characteristics & $\mathbf{N = 1 1 8}$ & $\mathbf{\%}$ \\
\hline Educational Attainment & & 43.2 \\
\hline Primary and Elementary School & 51 & 39.0 \\
\hline High School & 46 & 17.8 \\
\hline Bachelor's or Higher Degree & 21 & 19.5 \\
\hline Employment Status & 23 & 80.5 \\
\hline Employed & 95 & \\
\hline Non-employed & & \\
\hline Family Type & 114 & 96.6 \\
\hline Nuclear Family & 4 & \\
\hline Extended Family & & \\
\hline
\end{tabular}

Table 2: Distribution of the characteristics of the pregnancy and postpartum period of the mothers.

\begin{tabular}{|c|c|c|}
\hline Characteristics & $\mathbf{N = 1 1 8}$ & \% \\
\hline Pregnancy & & 74.6 \\
\hline Primipara & 30 & 25.4 \\
\hline Multipara & 88 & 50.0 \\
\hline Pregnancy intention & 59 & 40.7 \\
\hline Intended and planned & 48 & 9.3 \\
\hline Intended but unplanned & 11 & \\
\hline Unintended & & \\
\hline Mode of delivery & 71 & \\
\hline C-section & & \\
\hline
\end{tabular}




\begin{tabular}{|c|c|c|}
\hline Normal delivery & 47 & 39.8 \\
\hline \multicolumn{3}{|l|}{ Problem during pregnancy } \\
\hline Yes & 11 & 9.3 \\
\hline No & 107 & 90.7 \\
\hline \multicolumn{3}{|l|}{ Problem during delivery } \\
\hline Yes & 1 & 0.8 \\
\hline No & 117 & 99.2 \\
\hline \multicolumn{3}{|l|}{ Baby's sex } \\
\hline Female & 61 & 51.7 \\
\hline Male & 57 & 48.3 \\
\hline \multicolumn{3}{|l|}{ Feeling after delivery } \\
\hline Happiness -Joy-Excitement & 80 & 67.8 \\
\hline Nothing & 24 & 20.3 \\
\hline Tearful & 14 & 11.9 \\
\hline \multicolumn{3}{|l|}{ Baby is of the sex you preferred } \\
\hline Yes & 100 & 84.7 \\
\hline No & 18 & 15.3 \\
\hline \multicolumn{3}{|c|}{ Baby is the of the sex your spouse preferred } \\
\hline Yes & 98 & 83.1 \\
\hline No & 20 & 94.1 \\
\hline \multicolumn{3}{|l|}{ Received information on baby care } \\
\hline Yes & 45 & 38.1 \\
\hline No & 73 & 61.9 \\
\hline \multicolumn{3}{|l|}{ Ready for maternity } \\
\hline Yes & 113 & 95.8 \\
\hline No & 5 & 4.2 \\
\hline \multicolumn{3}{|l|}{ Nick name } \\
\hline Yes & 14 & 11.9 \\
\hline No & 104 & 88.1 \\
\hline \multicolumn{3}{|l|}{ Received support for baby care } \\
\hline Yes & 89 & 75.4 \\
\hline No & 29 & 24.6 \\
\hline
\end{tabular}

Logistic regression analysis was conducted to test the following models were assessed using the Hosmer-Lemeshow Test, -2LL research question: "What are the factors affecting the level of value, Cox \& Snell R-Square, Nagelkerke R-Square, and classification mother-infant bonding in mothers of advanced age?" The results percentage, and both models were found to have a good fit [21,22]. are given in Table 3 and Table 4. The goodness of fit of these two

Table 3: Results of the logistic regression of Model 1.

\begin{tabular}{|c|c|c|c|}
\hline Forecast Variable & B & Wald's $\boldsymbol{\chi}^{2}$ & Odds \\
\hline Age & 0.330 & $6.130^{*}$ & 1.391 \\
\hline Educational attainment & & & 1.580 \\
\hline Primary and elementary school & -1.340 & 1.190 & 0.262 \\
\hline High school & -1.347 & 1.576 & 0.260 \\
\hline Bachelor's or higher degree (RG) & & & 0.001 \\
\hline Employment status & & 1.535 & \\
\hline Yes & -7.187 & & \\
\hline No (RG) & & & \\
\hline Occupation & & & \\
\hline
\end{tabular}




\begin{tabular}{|c|c|c|c|}
\hline Housewife & -0.205 & 0.020 & 0.814 \\
\hline \multicolumn{4}{|l|}{ Civil servant or worker (RG) } \\
\hline Income status & -0.001 & 2.313 & 0.999 \\
\hline Spouse's age & -0.046 & 0.277 & 0.955 \\
\hline Spouse's educational attainment & 0.271 & 1.016 & 1.311 \\
\hline Primary and elementary school & -0.374 & 0.044 & 0.688 \\
\hline High school & & 0.133 & \\
\hline \multicolumn{4}{|l|}{ Bachelor's or higher degree (RG) } \\
\hline \multicolumn{4}{|l|}{ Spouse's occupation } \\
\hline Civil servant & 0.616 & 2.381 & 1.851 \\
\hline Worker & -0.636 & 0.425 & 0.529 \\
\hline Self-employed (RG) & & 1.492 & \\
\hline $\begin{array}{l}\text { Hosmer and Lemeshow Test } \\
\text { (Chi-square) }\end{array}$ & & 3.827 & \\
\hline$-2 L L$ & & 124.445 & \\
\hline Cox \& Snell R Square & & 0.185 & \\
\hline Nagelkerke R Square & & 0.254 & \\
\hline Classification percentage & & 68.4 & \\
\hline $\mathbf{N}$ & & 118 & \\
\hline
\end{tabular}

Table 4: Results of the logistic regression of Model 2.

\begin{tabular}{|c|c|c|c|}
\hline Forecast Variable & B & Wald's $\chi^{2}$ & Odds \\
\hline \multicolumn{4}{|l|}{ Have another child? } \\
\hline Yes & -2.337 & $4.102^{*}$ & 0.097 \\
\hline \multicolumn{4}{|l|}{ No } \\
\hline \multicolumn{4}{|l|}{ Planned pregnancy? } \\
\hline Intended and planned & 0.706 & 1.096 & 2.027 \\
\hline \multirow[t]{2}{*}{ Intended but unplanned } & 1.070 & 0.466 & \\
\hline & 2.915 & & \\
\hline Unintended (RG) & & 1.026 & \\
\hline \multicolumn{4}{|l|}{ Mode of delivery } \\
\hline C-section & 2.209 & $10.430^{* *}$ & 9.109 \\
\hline \multicolumn{4}{|l|}{ Normal delivery (RG) } \\
\hline \multicolumn{4}{|l|}{ Infant's sex } \\
\hline Female & 0.492 & 0.732 & 1.635 \\
\hline \multicolumn{4}{|l|}{ Male (RG) } \\
\hline \multicolumn{4}{|l|}{$\begin{array}{l}\text { Is infant of the sex the mother } \\
\text { preferred? }\end{array}$} \\
\hline Yes & -1.666 & 2.754 & 0.189 \\
\hline \multicolumn{4}{|l|}{ No (RG) } \\
\hline \multicolumn{4}{|l|}{ Readiness for maternity } \\
\hline Yes & 3.926 & $4.367^{*}$ & 50.702 \\
\hline \multicolumn{4}{|l|}{ No (RG) } \\
\hline \multicolumn{4}{|l|}{ Received support in baby care? } \\
\hline Yes & -0.822 & 1.862 & 0.439 \\
\hline \multicolumn{4}{|l|}{ No (RG) } \\
\hline $\begin{array}{l}\text { Received information in relation } \\
\text { to baby care? }\end{array}$ & & & \\
\hline
\end{tabular}




\begin{tabular}{|c|c|c|c|}
\hline Yes & 1.641 & $6.457^{*}$ & 5.162 \\
\hline \multicolumn{4}{|l|}{ No (RG) } \\
\hline $\begin{array}{c}\text { When the mother first saw her } \\
\text { infant }\end{array}$ & -0.014 & 1.294 & 0.986 \\
\hline $\begin{array}{l}\text { When the mother first cuddled her } \\
\text { infant }\end{array}$ & 0.011 & 0.867 & 1.011 \\
\hline $\begin{array}{l}\text { Hosmer and Lemeshow Test } \\
\text { (Chi-square) }\end{array}$ & \multicolumn{3}{|c|}{25.774} \\
\hline$-2 L L$ & \multicolumn{3}{|c|}{84.986} \\
\hline Cox \& Snell R Square & \multicolumn{3}{|c|}{0.435} \\
\hline Nagelkerke R Square & \multicolumn{3}{|c|}{0.600} \\
\hline Classification percentage & \multicolumn{3}{|c|}{89.8} \\
\hline $\mathrm{N}$ & \multicolumn{3}{|c|}{118} \\
\hline
\end{tabular}

RG: Reference Group; ${ }^{*} \mathrm{p}<0.05 ;{ }^{* *} \mathrm{p}<0.01$.

In the first logistic regression model 1 where motherinfant bonding is the dependent variable and the demographic characteristics are the independent variables, mother's age has a positive effect on mother-infant bonding. When mother's age increases by one, the probability of her bonding with her infant rises approximately by 39\% (1.39-1=0.39). Table 1 shows that mother's educational attainment, employment status, occupation; spouse's age, educational attainment, occupation, and family's income do not have any effect on the mother-infant bonding. In the second regression model 2 where mother-infant bonding is the dependent variable and the previous and current pregnancy characteristics, infant's sex, readiness for maternity, condition of receiving information and support in relation to baby care are independent variables, the condition of pregnancy planning, infant's sex, the condition that baby is of the sex the mother preferred, condition of receiving support in relation to baby care as well as information on when the mother saw and cuddled her new infant were found to have no effect on the mother-infant bonding.

The number of children in the family adversely affects the bonding by the mother. That is, it is safe to say that mothers that have a child have less bonding to their new infant than mothers that do not have a child. By comparing the mothers that had C-section with the mothers that had a normal delivery in Table 4, it is seen that the probability of bonding is higher for mothers that had C-section than the mothers that had a normal delivery. The probability of bonding is 50.702 times higher for mothers that felt ready for maternity than those that did not. According to Model 2, it can be said that the probability of bonding is higher for the mothers that receive information on baby care than those that do not. Receiving information on baby care positively affects the bonding of the mother to her new infant.

\section{Discussion}

Family is the social environment where an individual is provided with the care and support necessary to survive from the moment he/she comes into the world. Family is the social structure where the value judgments, normative rules and socialisation are experienced in the most serious and intense manner [23]. Motherfather-infant bonding plays a crucial role in the development process of the child. Mother is biologically and psychologically in a deep relationship with the infant. She is the first caretaker and protector of the infant as well as the first person with whom the infant establishes a relationship, whom the infant trusts and from whom the infant receives love from the first moments of the infant in its life [24]. The first minutes following birth are of vital importance for bonding, and this bond is further strengthened with the first social behaviour of the infant. According to Bowlby, bonding has a vital value from the viewpoint of the infant. Healthy mother-infant interaction behaviour facilitates the socioemotional, behavioural and cognitive development of the infant; furthermore it is affected the physical and psychological health of the infant [25].

The objective of this study is to identify the factors affecting the level of mother-infant bonding in advanced age pregnancies. The average MIBS score of the mothers that participated in the study was found to be $2.53 \pm 0.08$. In their study involving 78 mothers in the newborn unit, Bienfait et al. [26] found an average MIBS score above 2.00. In their study conducted with mothers and fathers, Figueiredo et al. [18] found that the MIBS score average of mothers was 5.69 and the MIBS score average of fathers was 6.25. A statistically significant difference was found in the logistic regression analysis conducted between the mother's age and mother-infant bonding score. When the mother's age increases even one-age, the probability of her bonding with her infant rises approximately by $39 \%(1.39-1=0.39)$. In a study conducted by Kavlak and Sirin in 2009, no statistically significant difference was found between the age groups of mothers and maternal bonding score averages $[27,28]$. In a study conducted by Sen in relation to maternal bonding, the maternal bonding scores of young mothers were found to be higher than those of mothers in the age group 38 and above. Similarly, Kinsey et al. [29] found that advanced age was associated with low maternal bonding. Figueiredo found a 
difference in the level of infant bonding of advanced-age mothers. In their study conducted to examine the level of maternal bonding in mothers with premature infants, Ozturk and Saruhan identified the mother's age as a significant variable [30].

Regarding other factors that may affect bonding, no relationship was found between parity and bonding in some studies, whereas the studies found that primiparas had a higher level of bonding, and the studies by Sen found that the level of maternal bonding decreased as the number of deliveries and children increased [31-33]. In our study, we found that the number of children in the family adversely affected the maternal bonding, which is a similar conclusion to that of the study by Korja et al. [34]. In other words, it is possible to say that multiparas have a lower level of maternal bonding than primiparas. Similarly to the results of our study, other studies confirm that primiparas have a higher level of maternal bonding. These results are similar to the results obtained in the relevant literature. While in some studies in the literature no relationship was found between the mode of delivery and the mother-infant bonding, the study conducted by Herguner et al. [35] on the relationship between the mode of delivery and the maternal bonding found that mothers who had given birth through C-section had a lower level of maternal bonding. In our study, one can see that that the probability of maternal bonding in mothers who had C-section is higher than that in the mother who had a normal delivery.

Mothers want to receive information on the matters relating to both their care and baby care after the delivery. Development of baby care skills and trust is quite important for a new mother [36]. In our study, the one may say that the probability of maternal bonding in the mothers who received information on baby care is higher than that in those who did not receive any information. Receiving information on baby care positively affects the bonding of the mother to the baby. Our study similarly found that the mothers who had received training in the antenatal period had a higher level of maternal bonding $[37,38]$. It was noted that the mothers-to-be who are prepared to delivery and postpartum period and receive information throughout their pregnancy have more sincere and positive behaviour towards their infants after the delivery [39]. In their study, Ozturk and Saruhan found that the average score of mothers who considered the information they had received on their baby was not adequate was lower than the score average of the mothers in other groups, and that the difference between them was statistically significant. In a study conducted by Sercekus and Baskale, they found, unlike our study, that the training given prior to delivery had no effect on mother-father-infant bonding [40].

Maternity is the combination of social roles and developmental components, behaviour and attitudes [41]. As noted by Alligood and Tonney, the acquisition of the "role of a mother", which can also be defined as the process in which mother learns the maternal behaviour, starts prior to conception and fully takes place in one year following the delivery. Maternity is the prerequisite to the bonding of the baby to its mother [42]. Our study found that the probability of bonding is 50,702 times higher for mothers that felt ready for maternity than those that did not. Maternal factors such as age, number of deliveries, educational attainment, employment status and social support are claimed to play a role in the acquisition of maternal role $[24,43]$.

\section{Conclusion}

It is known that advanced maternal age has been associated with adverse pregnancy outcomes. On the other hand, it was found that advanced age positively affected maternal bonding. Motherinfant bonding after pregnancies with advanced maternal age should be carefully considered, and studies should be conducted involving advanced age gravidas and normal gravidas.

\section{References}

1. Dildy GA, Jackson GM, Fowers GK (1996) Very advanced maternal age: pregnancy after age 45. Am J Obstet Gynecol 175: 668-174.

2. Mills TA, Lavender T (2010) Advanced maternal age. Obstet Gynaecol Reprod Med 21: 107-111.

3. Laopaiboon M, Lumbiganon P, Intarut N (2014) Advanced maternal age and pregnancy outcomes: a multicountry assessment. BJOG 121: 49-56.

4. Khalil A, Syngelaki A, Maiz N (2013) Maternal age and adverse pregnancy outcome: a cohort study. Ultrasound Obstet Gynecol 42(6): 634-643.

5. Newburn Cook CV, Onyskiw JE (2005) Is older maternal age a risk factor for preterm birth and fetal growth restriction? A systematic review. Health Care Women Int 26(9): 852-875.

6. Dietl A, Cupisti S, Beckmann MW, Schwab M, Zollner U Pregnancy and Obstetrical Outcomes in Women Over 40 Years of Age (2015) Pregnancy and Obstetrical Outcomes in Women Over 40 Years of AgePregnancy and Obstetrical Outcomes in Women Over 40 Years of AgePregnancy and Obstetrical Outcomes in Women Over 40 Years of Age. Geburtshilfe Frauenheilkd 75(8): 827-832.

7. Turkey Demographic and Health Survey (TDHS) (2013)

8. Martin JA, Hamilton BE, Ventura SJ, Osterman V, Wilson EC, et al. (2012) Births: Final Data for 2010. Natl Vital Stat Rep 61(1): 1-72.

9. Salem YS, Levy A, Wiznitzer A, Holcberg G, Mazor M, et al. (2011) A significant linear association exists between advanced maternal age and adverse perinatal outcome. Arch Gynecol Obstet 283(4): 755-759.

10. Nilsen AB, Waldenström U, Hjelmstedt A, Rasmussen S, Schytt E (2012) Characteristics of women who are pregnant with their first baby at an advanced age. Acta Obstet Gynecol Scand 91(3): 353-362.

11. Walker LO, Crain H, Thompson E (1986) Mothering behavior and maternal role attainment during the postpartum period. Nurs Res 35(6): 352-355.

12. Stark AM (1997) Psychosocial adjustment during - pregnancy: The experience of mature gravidas. J Obstet Gynecol Neonatal Nurs 26(2): 206-211.

13. Mercer RT, Walker LO (2006) A review of nursing interventions to foster becoming a mother. J Obstet Gynecol Neonatal Nurs 35(5): 568-582. 
14. Kinsey BC, Hupcey JE (2013) State of the science of maternal-infant bonding: A principle-based concept analysis. Midwifery 29(12): 13141320 .

15. Coban A, Saruhan A (2005) The role of nurses in mother-infant bond. Ege Üniversitesi Hemşirelik Yüksekokulu Dergisi 21: 89-96.

16. Calisir H, Karacam Z (2011) Factors associated with parenting behavior of mothers in the early postpartum period in Turkey. Nurs Health Sci 13(4): 488-494.

17. Lerum CW, LoBiondo-Wood G (1989) The relationship of maternal age, quickening, and physical symptoms of pregnancy to the development of maternal-fetal attachment. Birth 16(1): 13-17.

18. Figueiredo B, Costa R, Pacheco A, Pais A (2009) Mother to infant emotional involvement at birth. Matern Child Health J 13(4): 539-549.

19. Taylor A, Atkins R, Kumar R, Adams D, Glover V (2005) A new Motherto-Infant Bonding Scale: links with early maternal mood. Arch Womens Ment Health 8(1): 45-51.

20. Karakulak- Aydemir H, Alparslan Ö (2016) Adaptation of Mother to Infant Bonding Scale to the Turkish society: Aydın sample. J Contemp Med 6(3):188-199.

21. Hair JF, Anderson RE, Tatham RL (1998) Multivariate Data Analysis. (5 $5^{\text {th }}$ edn.); Upper Saddle River, Prentice Hall, New Jersey, USA.

22. Hosmer DW, Lemeshow S (2000) Applied Logistic Regression. (2 ${ }^{\text {nd }}$ edn.); Wiley \& Sons, New Jersey, USA.

23. Parsons T (2010) Social Structure \& Personality. ( $3^{\text {rd }}$ edn.); The free press, New York, USA, p. 1-10.

24. Benoit D (2004) Infant-parent attachment: Definition, types, antecedents, measurement and outcome. Paediatr Child Health 9(8): 541-545.

25. Korja R, Latva R, Lehtonen L (2012) The effects of preterm birth on mother-infant interaction and attachment during the infant's first two years. Acta Obstet Gynecol Scand 91(2): 164-173.

26. Bienfait M, Maury M, Haquet A, Faillie JL, Franc N, et al. (2011) Pertinence of the self-report mother-to-infant bonding scale in the neonatal unit of a maternity ward. Early Hum Dev 87(4): 281-287.

27. Kavlak O, Sirin A (2009) The Turkish version of maternal attachment inventory. International Journal of Human Sciences 6(1): 188-202.

28. Sen S (2007) Investigation of grandmother-mother-baby bond. Ege University, Unpublished master dissertation.

29. Kinsey BC, Baptiste-Roberts K, Zhu J, Kjerulff KH (2014) Birth-related, psychosocial, and emotional correlates of positive maternal-infant bondingin a cohort of first-time mothers. Midwifery 30(5): 188-194.
30. Ozturk R, Saruhan A (2013) Invastigation of correlation between depression and maternal attachment of mothers with 1 to 4-monthold premature babies treated at the hospital. Hemșirelikte Araștırma Geliştirme Dergisi 1:32-47.

31. Condon JT, Esuvaranathan V (1990) The influence of parity on the experience of pregnancy: a comparison of first- and second-time expectant couples. Br J Med Psychol 63(4): 369-377.

32. Berryman JC, Windridge KC (1996) Pregnancy after 35 and attachment to the fetus. J Reprod Infant Psychol 14: 133-143.

33. Redshaw M, Hennegan J, Kruske S (2014) Holding the baby: Early mother-infant contact after childbirth and outcomes. Midwifery 30(5): 177-187.

34. Korja R, Savonlahti E, Haataja L, Lapinleimu H, Manninenet H, et al. (2009) Attachment representations in mothers of preterm infants. Infant Behav Dev 32(3): 305-311.

35. Herguner S, Cicek E, Annagur A, Herguner A, Ors R (2014) Association of delivery type with postpartum depression, perceived social support and maternal attachment. The Journal of Psychiatry and Neurological Sciences 27: 15-20.

36. Pillitteri A (2003) Maternal child health nursing: Care of childbearing \& childbearing family. Lippincott Company, Philadelphia, USA. pp. 595717.

37. Abasi E, Tafazzoli M, Esmaily H, Hasanabadi H (2013) The effect of maternal-fetal attachment education on maternal mental health. Turkish Journal of Medical Sciences 43: 815-820.

38. Toosi M, Akbarzadeh M, Sharif F, Zare N (2014) The reduction of anxiety and improved maternal attachment to fetuses and neonates by relaxation training in primigravida women. Women's Health Bulletin 1: e18968.

39. Waldenström U, Rudman A, Hildingsson I (2006) Intrapartum and postpartum care in Sweden: women's opinions and risk factors for not being satisfied. Acta Obstet Gynecol Scand 85(5): 551-560.

40. Sercekus P, Baskale H (2016) Effects of antenatal education on fear of childbirth, maternal self-efficacy and parental attachment. Midwifery 34: 166-172.

41. Hammes T, Sebold LF, Kempfer SS, Reis-Girondi JB (2014) Nursing care in postpartum adaptation: perceptions of Brazilian mothers. Journal of Nursing Education and Practic 4(12): 125-133.

42. Alligood MR, Tonney AM (2006) Nursing Theory, Utilization \& Application. America Mosby Company pp. 393-399.

43. Nelson A (2003) Transition to motherhood. J Obstet Gynecol Neonatal Nurs 32(4): 465-477.

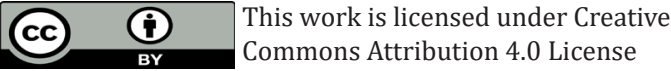

To Submit Your Article Click Here:

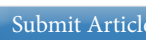

DOI: $10.32474 /$ LOJNHC.2018.01.000102

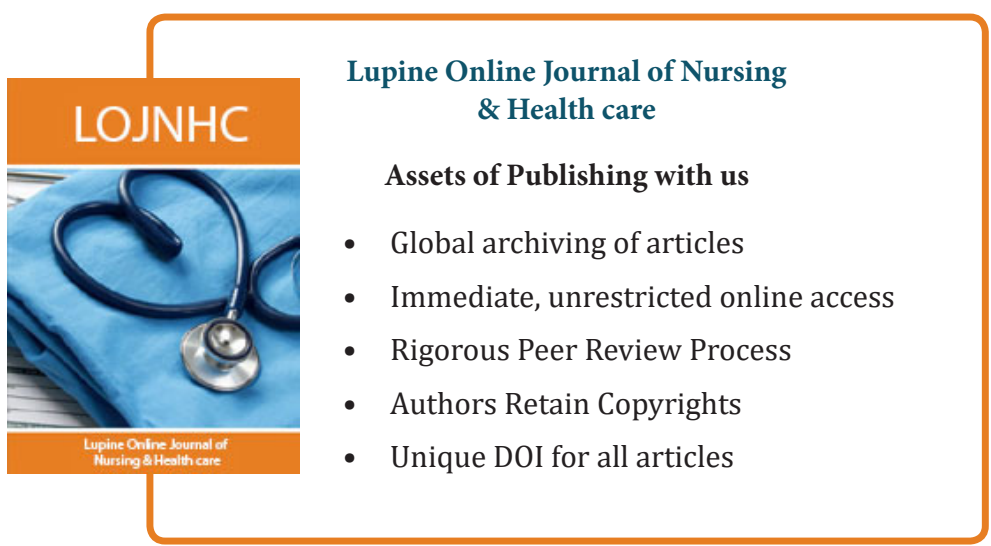

